\title{
Sex-specific spectral tuning for the partner's song in the duetting bushcricket Ancistrura nigrovittata (Orthoptera: Phaneropteridae)
}

Accepted: 18 March 1994

\begin{abstract}
The song of the male bushcricket Ancistrura nigrovittata consists of a sequence of verses. Each verse comprises a syllable group, plus, after about $400 \mathrm{~ms}$ a single syllable serving as a trigger for the female response song. The carrier frequency of the male song spectrum peaks at around $15 \mathrm{kHz}$, while the female song peaks at around $27 \mathrm{kHz}$. The thresholds of female responses to models of male songs are lowest for song frequencies between 12 and $16 \mathrm{kHz}$ and therefore correspond to the male song spectrum. The threshold curve of the female response to the trigger syllable at different frequencies has the same shape as the tuning for the syllable group. Phonotactic thresholds of male Ancistrura nigrovittata to synthetic female responses at different frequencies are lowest between 24 and $28 \mathrm{kHz}$ and thereby correspond to the female song spectrum and clearly differ from female response thresholds. Activity of the tympanic fibre bundle of both sexes is most sensitive between 15 and $35 \mathrm{kHz}$ and therefore not specifically tuned to the partner's song. Individual behavioural thresholds have their minimum within $10 \mathrm{~dB}$ of the values of tympanic thresholds.
\end{abstract}

Key words Orthoptera - Tettigonioidea

Song frequency $\cdot$ Song recognition $\cdot$ Sex difference

\section{Introduction}

In several groups of bushcrickets, e.g. in Ephippigerinae (Bradyporidae) and in Phaneropteridae, not only males produce songs but females respond by a song of their own [review: Robinson (1990)]. The stridulatory appara-

S. Dobler ${ }^{1} \cdot$ A. Stumpner ${ }^{2}(\varangle) \cdot$ K.-G. Heller

Institut für Zoologie der Universität Erlangen, Staudtstrasse 5, D-91058 Erlangen, Germany

Present addresses:

${ }^{1}$ EPO Biology, University of Colorado, Campus Box 334,

Boulder, CO 80309, USA

2 I. Zoologisches Institut der Universität Göttingen,

Berliner Str. 28, D-37073 Göttingen, Germany tus on the forewings has most probably evolved independently in males and females (Hartley et al. 1974; Nickle and Carlysle 1975; Heller and von Helversen 1986; Zhantiev and Korsunovskaya 1990). Nevertheless, the frequency spectra of male and female songs usually are similar, even if the elytra of males are larger (Nickle 1976; Hartley and Robinson 1976; Heller and von Helversen 1986; Robinson et al. 1986).

The songs of many phaneropterid species are relatively sharply tuned (Heller and von Helversen 1986; Heller 1988 ) and the frequency-spectra often are species specific. How can this specific information be utilized in intraspecific communication? Two principle answers may be given: at first, a narrow frequency spectrum improves the signal to noise ratio in the auditory system of a receiver, if its sensitivity is tuned to the sender's song frequency. Second, the receiver could recognize the frequency and could discriminate conspecific from heterospecific or from predator signals. In the best case, it even could discriminate between different conspecific individuals. The most clearly documented example for frequency discrimination comes from flying crickets, which exhibit positive phonotaxis to low-frequency sound, but negative phonotaxis to ultrasound (Moiseff et al. 1978; Nolen and Hoy 1986). Behavioural results from various bushcricket species indicate that frequency is a factor during phonotaxis; however, due to complex frequency spectra or because the neuronal sensitivity at different frequencies remains unknown, in most studies intensity cannot be ruled out as the factor actually causing response differences (Latimer and Sippel 1987; Bailey and Yeoh 1988; Gwynne and Bailey 1988). Only in the non-flying bushcricket Leptophyes punctatissima has it been demonstrated that male phonotaxis is more sharply tuned than the hearing threshold of the whole auditory organ (Hardt 1988). For a demonstration of frequency recognition, knowledge of auditory tuning is indispensable since the highest sensitivity of the auditory system is not necessarily tuned to the song frequency [Bailey and Römer (1991); Mason (1991); see also Popov (1990), for cicadas]. 
In the acoustic communication system of the bushcricket Ancistrura nigrovittata (Phaneropteridae) the male produces a song with a complicated temporal pattern (Heller and von Helversen 1986). Its song comprises a syllable group, most important for species recognition, and a single syllable serving as a trigger for the female reply (Dobler et al. 1994). We will demonstrate that males and females of this species in addition produce songs with different carrier frequencies. This raises several questions: is male and female behaviour, which can be elicited by the partner's song, sex-specifically tuned to the different frequencies? Is the spectral tuning of the female's behaviour identical for the two elements of the male song, which obviously serve different functions? How do behavioural tuning and auditory tuning correlate?

\section{Material and methods}

\section{Animals and song analysis}

The experimental animals were captured as nymphs in southern Yugoslavia (Makedonia) and northern Greece. In the laboratory the animals were kept at room temperature in natural daylight. Adult females and males were kept acoustically isolated from each other. The songs were recorded on magnetic tape, digitized and evaluated on a FFT-spectrum analyzer (MEDAV). For details see Dobler et al. (1994).

\section{Female response behaviour}

Female response behaviour was analysed in a computer-controlled setup (von Helversen 1979). The female was placed in a small cage within an anechoic chamber at $30^{\circ} \mathrm{C}$. After a stimulus comprising a verse was broadcast via a speaker within the chamber, the computer monitored female responses for a defined time before generating the next verse. The stimuli consisted of bandpass filtered white noise (KEMO VBF8, VBF9; $48 \mathrm{~dB}$ per octave). Al] intensity values are given in $\mathrm{dB}$ SPL (re. to $2 \cdot 10^{-5} \mathrm{~Pa}$ ). For more details of the setup see Dobler et al. (1994).

To establish the behavioural threshold at different frequencies the following stimulus program was used: the first stimulus of any frequency started with the lowest (in any case subthreshold) intensity. Seven verses were presented and any responses between the trigger syllable and the beginning of the next syllable group were monitored. If no reply was registered, then after a 15 -s pause a 3 $\mathrm{dB}$ louder stimulus was given. If a female answered, however, the stimulus intensity was decreased in 3-dB steps until the female stopped responding. Then the intensity was increased again until a predefined number of stimuli had been presented. The lowest answered intensity of each decreasing intensity scan was assigned one point and the number of points were cumulatively displayed in dependence of intensity. The function plateaued at the highest threshold value found. The intensity corresponding to the $50 \%$ value of that plateau was defined as mean threshold. The advantage of this method compared with calculating arithmetic means is that there is a smaller weighting of single runs, where the female only answered at a very high intensity - which may happen if a female is feeding or not motivated to respond. At the end of a program a complete intensity scan was run from the lowest intensity to the highest possible intensity for the respective frequency and responses were registered at every intensity. Then the next frequency was tested. A complete stimulus program lasted for about $\mathrm{I} \mathrm{h}$ and was automatically restarted. For testing intra-individual variability, however, an evaluation was done for every completed frequency scan during, for example, a 5-h experiment.
Male phonotaxis

For phonotaxis experiments a male was set on a platform in an anechoic room at $30^{\circ} \mathrm{C}$. A microphone registered the male song. A logic circuit and an interactive microprocessor (Rockwell AIM65) triggered a synthetic response with the species specific time delay of $30 \mathrm{~ms}$ from the onset of the single syllable of a male verse. As a synthetic response we used a sine wave signal of $1.5 \mathrm{~ms}$ duration with a short rising and a longer falling ramp, similar to the female response song.

When a male started singing spontaneously, for a first test a $32-\mathrm{kHz}$ response of $55 \mathrm{~dB}$ was presented. All males immediately started to orient towards the speaker. In following tests, for each frequency suprathreshold intensities were given initially and then the intensity was decreased in 6-dB steps. If the male showed any type of phonotactic response the position of the speaker was changed by about $90^{\circ}$ before the next stimulus was given. The distance between speaker and male was always kept at $20 \mathrm{~cm}$. If the male ceased to orient towards the speaker, the intensity was raised by $6 \mathrm{~dB}$ and then the threshold was determined in decreasing 3-dB steps. A maximum of 15 artificial responses was presented per intensity. As threshold we took the lowest value, at which at least three out of five trials evoked a phonotactic reaction.

\section{Electrophysiology}

For recordings of tympanic activity the animals were briefly anaesthetized with $\mathrm{CO}_{2}$ and mounted dorsal side up on a free standing holder using a resin-wax mixture. The frontal legs were fixed at right angles to the body's long axis and sagittal plane. The tibiae were oriented perpendicularly to the femur and the tarsi attached to a thin wire. The preparation was located in a sound-damped chamber $38 \mathrm{~cm}$ away from a piezoelectric speaker. The stimuli consisted of bandpass filtered white noise (Kemo VBF9), which was amplitude modulated under computer control (AIM 65): a stimulus had a $35 \mathrm{~ms}$ duration with 1.5 -ms rising and falling ramp and was repeated every $0.5 \mathrm{~s}$. Calibration was done as for behavioural experiments, intensity was varied in $3-\mathrm{dB}$ steps. For examining the effect of sound from different directions the whole animal was reoriented and a new recording was made each time.

Summed action potentials of the tympanic fibre bundle were recorded in the distal half of the femur through a small hole cut in the dorsal cuticle. The potentials were recorded by a suction electrode with a thin, flexible tip (opening around $0.1 \mathrm{~mm}$ ). The least intensity at which activity of the nerve coupled to the stimulus (judged by means of headphones and oscilloscope) was defined as threshold. For reliability of this method see Stumpner and Heller (1992).

\section{Results}

Frequency spectra of male song

and female response song

The calling song of male Ancistrura consists of a sequence of verses, each verse comprising several syllables which form a 'syllable group'. After a definite interval a single syllable is produced which serves as a trigger for the female response (Fig. 1). Each syllable comprises three to four pulses with very short intervals (about 1 $\mathrm{ms}$ ). All syllables have the same carrier frequency with a maximum energy between 10 and $17 \mathrm{kHz}$ (Fig. 1). The female response song usually consists of one pulse only with a maximum energy between 20 and $35 \mathrm{kHz}$. The purity of the songs can be assessed by the quality factor $\left[Q_{3 \mathrm{~dB}}\right.$ value, giving the ratio of the loudest frequency and 

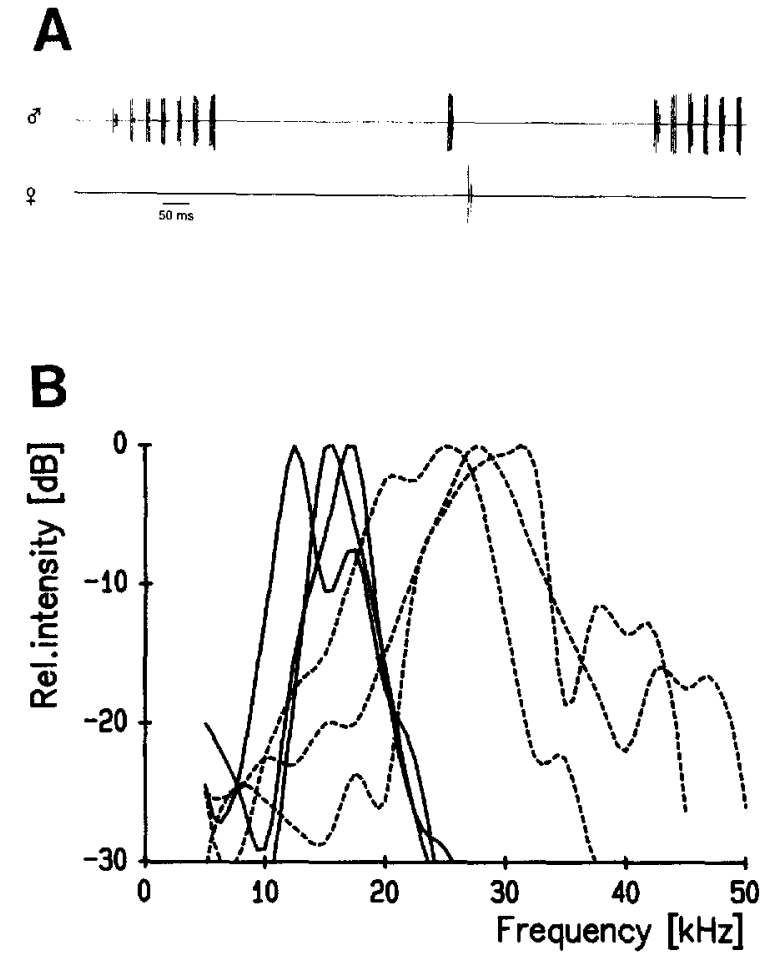

Fig. 1 A Song pattern of the male calling song (upper trace) and the female response (lower trace) in Ancistrura nigrovittata. B Song spectra of songs of three males (solid lines) and three females (dashed lines). Note that the female songs have their maximum energy at about double the frequency of the male songs

the spectral width at a $3 \mathrm{~dB}$ lower level, see BennetClark (1989)], and lies between 5.2 and 11.7 for males and between 3.3 and 10.0 for females [compared to 28 for Gryllus campestris, Bennet-Clark (1989)]. In males, however, this quality factor decreases with age and songs become more broad banded [compare also Hartley and Stephen (1989)]. The carrier frequency of both male and female songs seems to be mainly determined by forewing resonances and does not depend on temperature (tested for one male between 16 and $31^{\circ} \mathrm{C}$ ).

\section{Spectral tuning of female response behaviour}

Females respond to artificial song models in the same manner as to natural calls. Therefore, the response songs can be taken as a measure for their acceptance of a signal as species specific (Dobler et al. 1994). Most females respond to a song model of optimally effective temporal parameters if it is composed of "white noise" containing frequencies between 2 and $40 \mathrm{kHz}$, at an intensity of 70 dB SPL (Dobler et al. 1994). Since the male song, however, only contains a frequency band centering around 15 $\mathrm{kHz}$, the effectiveness of models of different carrier frequencies was tested.

The threshold functions of five females in Fig. 2A demonstrate that actually not all frequencies are equally effective. Measured in 4-kHz increments, the female's re-
A
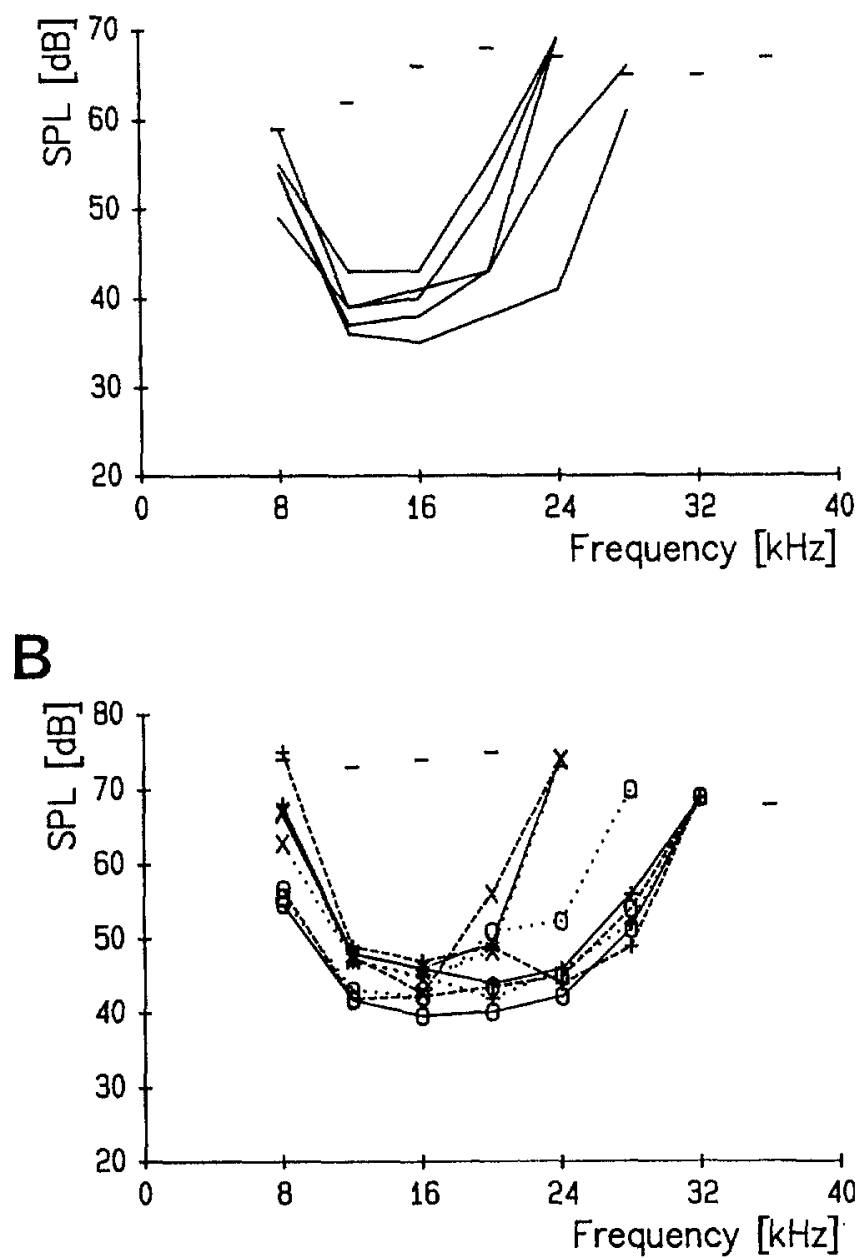

Fig. 2A,B Spectral tuning of the female's responses to models of the male song. A gives the thresholds of the response functions of five different females $(n=200-360$ stimuli per data point). The maximum sound pressure tested for each frequency is indicated by a horizontal bar. B Spectral tuning of three representative female's responses (indicated by different symbols) to different parts of a model of the male song (indicated by different line styles). The threshold curve for the syllable-group, for the single trigger-syllable and for the complete model are nearly identical. The maximum sound pressure tested for each frequency is indicated by a horizontal bar. $n$ per data point $=138-486$

sponses are most sensitive to models between 12 and 16 $\mathrm{kHz}$. Within the sound pressure range between 50 and 55 dB SPL, no female responded below $8 \mathrm{kHz}$ and only one above $24 \mathrm{kHz}$. The threshold drops on average by about $20 \mathrm{~dB}$ per octave between $12 \mathrm{kHz}$ and $8 \mathrm{kHz}$ and increases by $20-60 \mathrm{~dB}$ per octave between $16 \mathrm{kHz}$ and 20 $\mathrm{kHz}$. There is some inter-individual variability, especially in the high-frequency range. However, the intra-individual variability, which can be observed in subsequent tests of the same female, is very similar and covers the same frequency range.

As mentioned above, every verse of the male song comprises two different parts, a syllable group and a trig- 
A

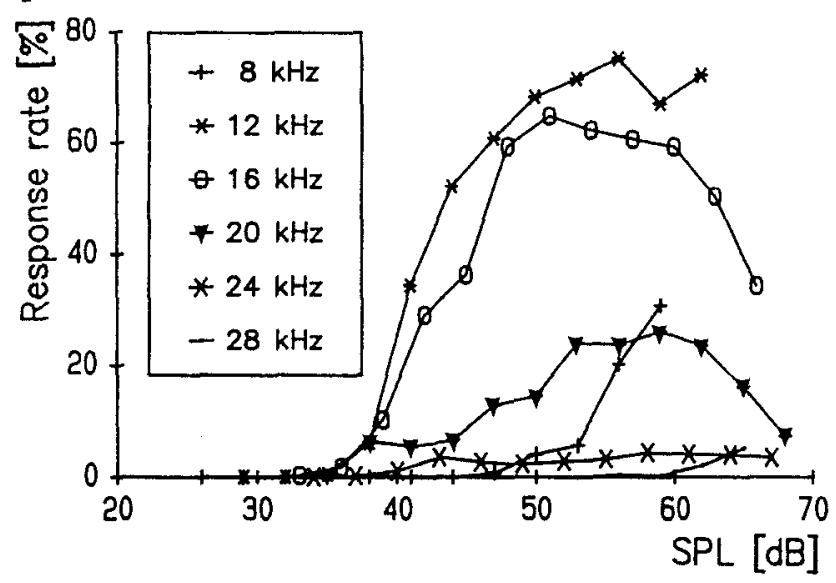

B

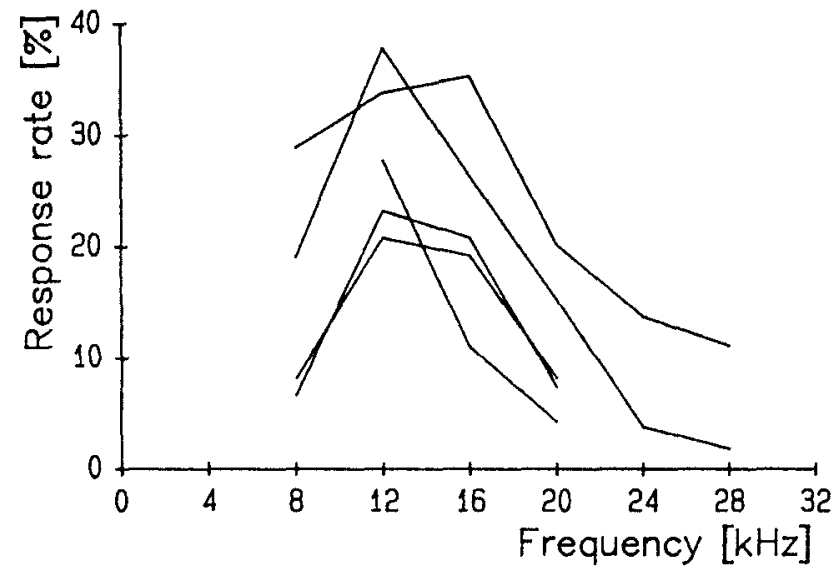

Fig. 3 A Rate of female responses in dependence of intensity. Different response functions correspond to the indicated frequencies. Response functions give the means of five females ( $28 \mathrm{kHz}$ : four females). Note that different response functions not only differ in threshold ( $\mathrm{dB})$ but also in steepness and in the maximum response rate. $B$ Response rates of five individual females in dependence of frequency. Evaluated are only data of the first two intensities (3-dB steps) above the response threshold at the respective frequencies. $n$ per data point $=119-749$

ger syllable. Moreover, the main function of the syllable group seems to be species recognition, while the main function of the single syllable obviously is to trigger the female response (Dobler et al. 1994). Therefore, it was conceivable that syllable group and trigger syllable are evaluated by different neuronal networks and that their processing could involve different spectral tuning. To test this hypothesis, the response functions of several females were examined when frequencies were varied for the whole model or either for the syllable group or the trigger only. Invariant song parts were kept at $16 \mathrm{kHz}$ and 50 $\mathrm{dB}$ SPL, which is well within the optimally effective range for all females. The results for three representative individuals are given in Fig. 2B. They very clearly demonstrate that the different parts of a song are processed by identically tuned filters.

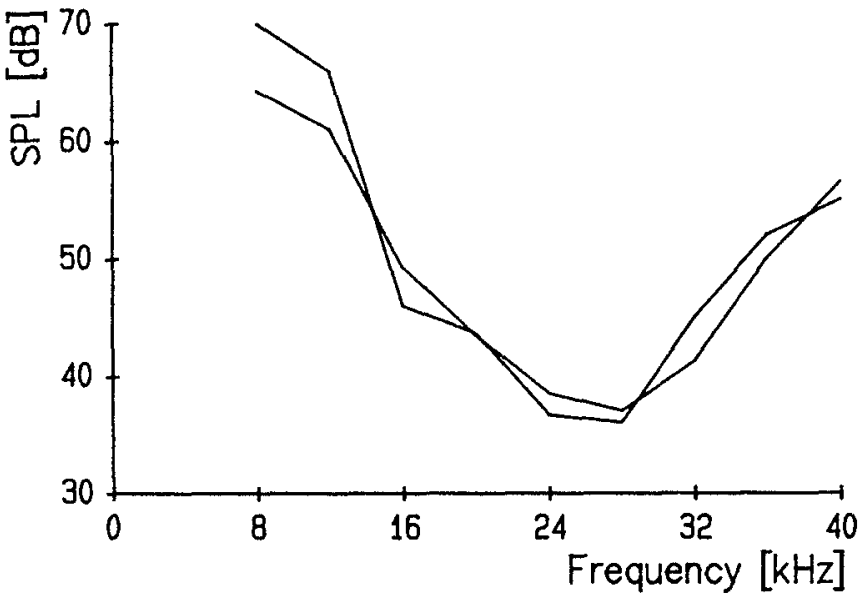

Fig. 4 Spectral tuning of the male's phonotactic behaviour elicited by synthetic responses to its own song. The threshold functions of two males (averaged from 3 days) are given. $n=9-56$ trials per frequency

Different frequencies not only evoked different response thresholds, but evoked different responses in females in a second way: if one plots the female response rate as a function of intensity (Fig. 3A, mean of five females), clear differences in steepness of response functions for different frequencies become obvious. Only those frequencies with the lowest threshold (12 and 16 $\mathrm{kHz}$ ) elicit high response rates, peaking at about $15 \mathrm{~dB}$ above threshold. Other frequencies render less steep functions which reach much lower maximum response rates - most clearly seen for $20 \mathrm{kHz}$ in Fig. 3A. At least at higher frequencies $(16 \mathrm{kHz}, 20 \mathrm{kHz})$, an additional drop in response frequency becomes apparent about $20-25 \mathrm{~dB}$ above threshold. If one takes only a 6 -dB-intensity range above the respective threshold of five individual females, and plots the percentage of stimuli answered as a function of frequency (Fig. 3B), remarkable differences in effectiveness become apparent. For all individuals it holds true that those frequencies, at which the threshold is lowest, are also best responded in the suprathreshold range.

\section{Spectral tuning of male phonotaxis}

When a female responds to a male's song, the male will start to move towards the female. When the female is replaced by a speaker and an artificial response is presented, the phonotaxis will be directed towards the speaker and frequency and intensity of the stimulus can be varied. Figure 4 gives the spectral tuning of positive phonotaxis of two different males. The maximum sensitivity is found between 24 and $28 \mathrm{kHz}$. The thresholds drop by $30-45 \mathrm{~dB}$ per octave between 12 and $16 \mathrm{kHz}$ but by much less between 8 and $12 \mathrm{kHz}$. The thresholds increase by about $30 \mathrm{~dB}$ per octave between 28 and 40 $\mathrm{kHz}$. These data are confirmed by three more males, for which no complete tuning curves were measured. 
A
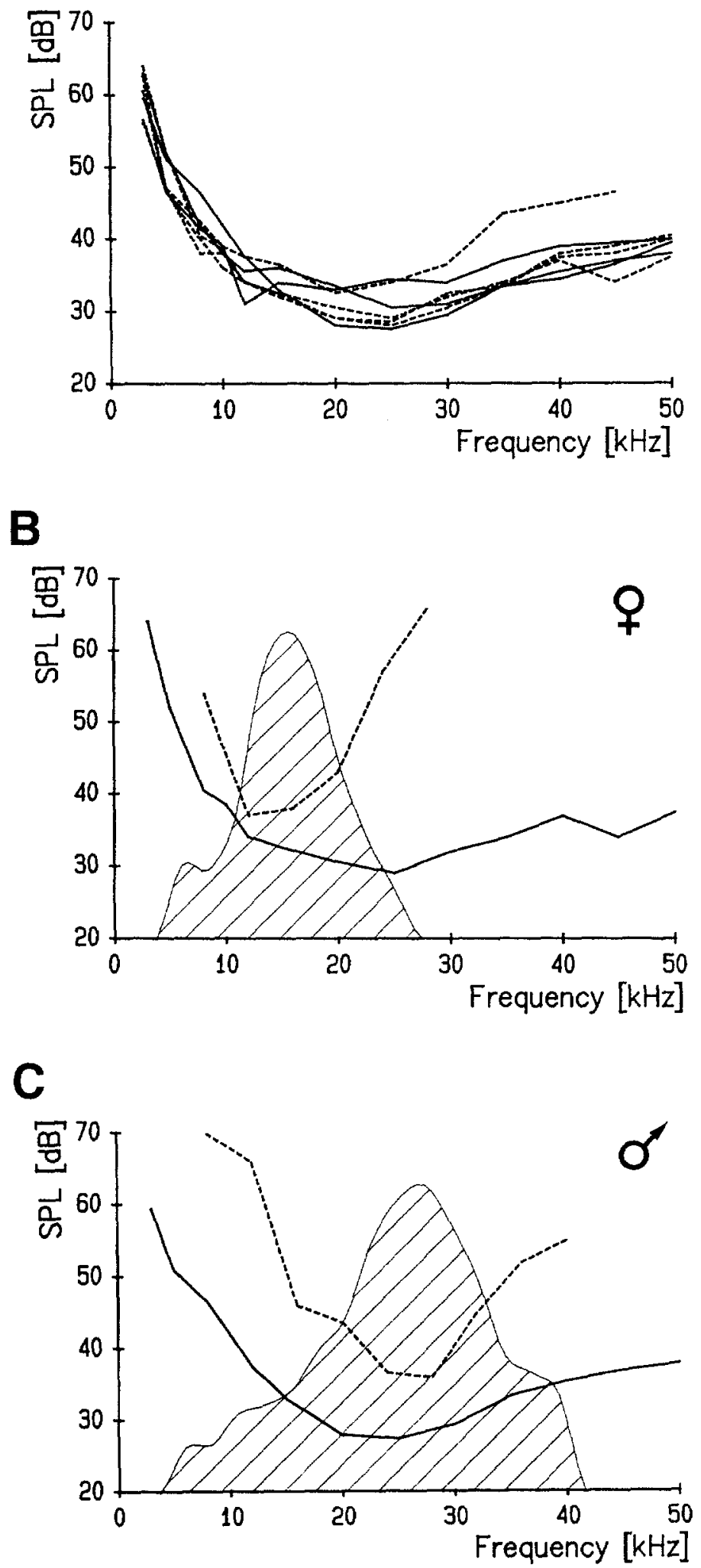

Fig. 5 A Auditory thresholds as a function of frequency measured as the least noticeable sound pressure at which summed activity coupled to the stimulus could be detected in the tympanic nerve. The data of four females (dashed lines) and three males (solid lines) are given. B Comparison of hearing threshold (summed
When presenting intensities above the behavioural threshold, three different behaviours can be observed: close to the threshold the males often slowly swing the thorax from left to right as if directing the auditory spiracles towards the sound source. With higher intensities the males mostly walk towards the speaker while continuing to sing. At intensities $20 \mathrm{~dB}$ above threshold or higher the males usually immediately jump towards the sound source. However, during the course of an experiment there seemed to be some sort of adaptation or habituation with high-intensity reactions becoming less and less likely.

Hearing ranges and behavioural tuning

To assess the differences in behavioural tuning between males and females it is necessary to know the tuning of the auditory organs of both sexes. Auditory tuning was measured in a whole-leg-nerve recording with the animals oriented at $0^{\circ}, 90^{\circ}, 180^{\circ}$ or $270^{\circ}$ towards the speaker $\left(90^{\circ}\right.$ meaning speaker ipsilateral to the recorded ear). In all individuals and at most frequencies the $90^{\circ}$-values gave the lowest thresholds, with few exceptions below $10 \mathrm{kHz}$, where frontal sound was slightly more effective. The $90^{\circ}$-tuning curves are shown for four females and three males in Fig. 5A. Two facts become immediately apparent: the tuning is relatively broad with a maximum sensitivity between 15 and $35 \mathrm{kHz}$ and there is no sex difference of auditory thresholds.

If one compares behavioural threshold and auditory threshold of the same individual (Figs. 5B,C), it seems that in both sexes the behaviour at the most effective frequency starts very close to hearing threshold. The behaviourally effective range clearly is only a portion of the complete hearing range of the individual and this portion is a different one in males and females. The differences between behavioural threshold and hearing threshold at 12 and $28 \mathrm{kHz}$ for example are 3 and $35 \mathrm{~dB}$ in the female, but 28 and $7 \mathrm{~dB}$ in the male.

\section{Discussion}

Discrimination of frequencies by males and females

Our results present clear evidence that in male and female Ancistrura nigrovittata only a part of the hearing range is effective for recognition of the partner's song. Among bushcrickets this has been demonstrated only for

activity of the tympanic nerve, solid line) and behavioural threshold (response behaviour, broken line) in an individual female. The shaded area gives the frequency spectrum of the male call (means of 12 individuals). C Comparison of hearing threshold (solid line) and behavioural threshold (positive phonotaxis, broken (ine) in an individual male. The shaded area gives the frequency spectrum of the female call (means of three individuals). The hearing thresholds in $\mathbf{B}$ and $\mathbf{C}$ were measured after the end of behavioural tests 
one other species, namely Leptophyes punctatissima (Hardt 1988). A difference of behavioural tuning between the sexes of bushcricket species has not been described so far. However, sex-specific hearing thresholds have been found (Bailey and Römer 1991; Stumpner and Heller 1992).

The ability to discriminate between different frequencies may have several advantages. Flying crickets discriminate between conspecific low-frequency calling songs and high-frequency predator signals (Nolen and Hoy 1986) and flying locusts steer away only from ultrasound although they also hear low frequencies (Robert 1989). For bushcrickets several hypotheses have been tested in the context of frequency discrimination: song frequency seemed to be used in male-male competition in Tettigonia cantans, since dominant males in the field had a significantly lower pitched song than subordinate males (Latimer and Schatral 1986). Moreover, females seemed to choose males with lower pitched songs, but song spectra were complex and intensity was a very effective parameter as well (Latimer and Sippel 1987). The relative content of high frequencies might indicate the distance of a male (Römer 1987; Kalmring et al. 1990). Females of Requena verticalis, by choosing songs with a louder high-frequency component, might simply choose the closer male and thereby minimize their risk of predation during phonotaxis (Bailey and Yeoh 1988). Many bushcrickets produce large spermatophores and, at least at certain times of the season, larger males of a zaprochiline species producing lower pitched songs also produced larger spermatophores. Therefore, it would have seemed to be advantageous for the females to choose lower pitched songs, but phonotaxis experiments failed to show a respective preference of females (Gwynne and Bailey 1988). Frequency, in addition to temporal pattern obviously can serve as a cue for species recognition in Ancistrura, since females only respond to models with the species-specific carrier frequency. Choice experiments, proving the effectivity of this recognition process, however, were not performed.

\section{Sex differences in song frequency}

In Ancistrura nigrovittata males and females differ in their song frequencies. This is not the case for any of the related species investigated (Heller and von Helversen 1986). The song-frequency differences correlate with differences in the behavioural tuning. Although we have no detailed knowledge about song intensities in $A n$ cistrura, in this group and other orthopterans females usually have less intense songs than males [for Leptophyes see Zimmermann et al. (1989)] and therefore the song intensity of the females limits the communication distance. This should be even more pronounced in $\mathrm{An}$ cistrura, since females produce higher song frequencies than males. Higher frequencies are more strongly attenuated with increasing distance than are lower frequencies. On the other hand, a higher song frequency can be more easily localized during male phonotaxis (Bailey and Yeoh 1988). In addition, the song frequency of the female corresponds well to the normal correlation between body size and song frequency in this bushcricket group (K.-G. Heller, unpublished data). Ancistrura males, however, have relatively large elytra and produce songs of unusually low frequency. There might be several advantages for the males to use lower song frequencies, e.g. indicating a larger body-size and/or a higher male quality to females. Lower frequencies might ensure a higher success probability in male-male competition (see above) or allow a larger communication distance.

\section{Neuronal processes underlying song recognition}

The behaviour of male and female Ancistrura nigrovittata is differently tuned. Their hearing thresholds, however, are virtually identical in the frequency range tested. The difference seems to be manifested at the level of central processing, although peripheral differences cannot be ruled out from whole-nerve recordings. Additionally, the behavioural tuning functions of males and females cover only a portion of the hearing range. The behavioural tuning, in the extreme, might represent the tuning of only one receptor cell and might in addition be sharpened by central processing. The tuning is similar to that published for receptors with best frequencies between 10 and $30 \mathrm{kHz}$ in various bushcrickets (Kalmring et al. 1978; Oldfield 1983; Römer 1987; Hardt 1988; Kalmring et al. 1990). Moreover, there are clear indications that in females, even above threshold, different frequencies are also differently effective. This could mean that a single receptor codes the temporal pattern of a signal differently, depending on frequency. Such a dependence has not been described in bushcricket receptors so far. On the other hand, more receptors than just one could contribute to the behavioural tuning. These receptors might be most sensitive at the song frequency, but might have different sharpness of tuning [for cells with identical characteristic frequency but different thresholds see Oldfield (1984) and Kalmring et al. (1990)]. The consequence would be that their summated activity would be strongest close to the song frequency. Another possibility would be that receptors tuned to frequencies lower or higher than the song frequency have inhibitory effects on the behaviour. In that case, we would expect that receptors tuned to the partner's song have a broader tuning than the behaviour. In accordance with this hypothesis we find that the female response frequency decreased at 20-25 dB above threshold, at least to $16 \mathrm{kHz}$ and $20 \mathrm{kHz}$ models (Fig. 3A). This decrease might be caused by a deteriorated neuronal representation of the temporal pattern of the song at higher intensities due to inhibition. To test this hypothesis, some behavioural experiments were performed with a two-tone paradigm (S. Dobler, unpublished data). The results, however, gave no indications for the existence of inhibitory processes in this context. 
A sharpening of tuning by frequency-dependent inhibition has been described for bushcrickets (Oldfield and Hill 1983; Römer 1987; Hardt 1988) and therefore might be found in the central nervous system of Ancistrura as well. Central processing seems to be especially suited to produce frequency-dependent differences above threshold. At least for females, another aspect might become interesting on the interneuronal level: the two parts of a male verse probably are guided through different neuronal pathways. The syllable group is important for species recognition and the processing network most certainly involves brain neurons as has been shown for other orthopterans [crickets: Schildberger (1984), Pires and Hoy (1992); grasshoppers: Bauer and von Helversen (1987)]. Two facts corroborate this hypothesis: the relatively long time period between the syllable group and the single syllable in Ancistrura, and the finding that for male phonotaxis in Leptophyes the neuron with the closest correspondence between behavioural and neuronal tuning is a neuron ascending from the prothoracic ganglion, most probably to the brain (Hardt 1988). The single syllable in male songs of Ancistrura serves as a trigger and the female response occurs $20-30 \mathrm{~ms}$ later. This time probably is too short to involve a brain loop (Robinson 1990), although latencies as short as $25 \mathrm{~ms}$ during negative phonotaxis in crickets are believed to involve a brain loop (Nolen and Hoy 1986). Therefore neurons descending from the prothoracic ganglion or $\mathrm{T}$-shaped neurons might be involved in eliciting the motor response (Hardt 1988; Zhantiev 1971). Experiments with independent variation of frequency in the syllable group and in the trigger syllable (Fig. 2B) gave no indication that the two processes are differently tuned. This means that both networks have a common element or at least have identically tuned elements which determine the outputs of the two neuronal filters.

The situation found in Ancistrura nigrovittata contrasts with that found in the cicada Cystosoma saundersii where processing of frequency and temporal parameters seem to occur nearly independently of each other. Flying females only listened to the frequency of a signal for positive phonotaxis, while in the close range only male song models of appropriate temporal pattern could initiate female courtship behaviour, nearly independent of their frequencies (Doolan and Young 1989).

It may seem surprising that the threshold at the sensitivity peak of behaviour and the threshold of the auditory organ seem to be very close in both males and females. In the related species Leptophyes larger differences have been found, with about $20 \mathrm{~dB}$ in females (Hardt 1988). One possible reason for this discrepancy might be different methods for collecting the data: auditory thresholds give the summed activity of the whole nerve and might consistently lead to $\mathrm{dB}$ values which are higher than those found on the single cell level (in Leptophyes individual receptor cells had been measured). Preliminary single-cell recordings in Ancistrura, however, indicate correspondence of thresholds determined for single cells and those determined for the whole tympanic nerve. On the other hand, the song of Ancistrura is much more complex than that of Leptophyes. The neuronal network in Ancistrura might be especially adapted to evaluate the species specific temporal pattern at very low intensities. These hypotheses need to be tested in neurophysiological experiments.

Acknowledgements We express our gratitude to Otto von Helversen for many helpful suggestions, for his support throughout the study and for commenting on the manuscript. Dagmar von Helversen helped with numerous discussions and with supplying essential pieces of equipment. Alfred Schmiedl helped a lot with technical problems. George Boyan helped essentially to improve the English.

\section{References}

Bailey WJ, Römer H (1991) Sexual differences in auditory sensitivity: mismatch of hearing threshold and call frequency in a tettigoniid (Orthoptera, Tettigoniidae: Zaprochilinae). J Comp Physiol A 169:349-353

Bailey WJ, Yeoh PB (1988) Female phonotaxis and frequency discrimination in the bushcricket Requena verticalis. Physiol Entomol 13:363-372

Bauer M, Helversen O von (1987) Separate localization of sound recognizing and sound producing neural mechanisms in a grasshopper. J Comp Physiol A 161:95-101

Bennet-Clark HC (1989) Songs and the physics of sound production. In: Huber F et al. (eds) Cricket behavior and neurobiology. Cornell Univ Press, Ithaca, pp 227-261

Dobler S, Heller K-G, Helversen O von (1994) Song pattern recognition and an auditory time window in the female bushcricket Ancistrura nigrovittata (Orthoptera, Phaneropteridae). J Comp Physiol A 175:67-74

Doolan JM, Young D (1989) Relative importance of song parameters during flight phonotaxis and courtship in the bladder cicada Cystosoma saundersii. J Exp Biol 141:113-131

Gwynne DT, Bailey WJ (1988) Mating system, mate choice and ultrasonic calling in a zaprochiline katydid (Orthoptera: Tettigoniidae). Behaviour 105:202-223

Hardt M (1988) Zur Phonotaxis von Laubheuschrecken: Eine vergleichend verhaltensphysiologisch/neuroanatomische Untersuchung. Dissertation Univ Bochum

Hartley JC, Robinson DJ (1976) Acoustic behaviour of both sexes of the speckled bushcricket Leptophyes punctatissima. Physiol Entomol 1:21-25

Hartley JC, Stephen RO (1989) Temporal changes in the quality of the song of a bushcricket. J Exp Biol 147:189-202

Hartley JC, Robinson DJ, Wayne AC (1974) Female response song in the ephippigerines Steropleurus stali and Platystolus obvious (Orthoptera, Tettigoniidae). Anim Behav 22:382-389

Heller K-G (1988) Bioakustik der europäischen Laubheuschrekken. Ökologie in Forschung und Anwendung Bd. 1: Verlag Josef Markgraf, Weihersheim

Heller K-G, Helversen D von (1986) Acoustic communication in phaneropterid bushcrickets: species-specific delay of female stridulatory response. Behav Ecol Sociobiol 18:189-198

Helversen $\mathrm{O}$ von (1979) Angeborenes Erkennen akustischer Schlüsselreize. Verh Dtsch Zool Ges 1979:42-59

Kalmring K, Lewis B, Eichendorf A (1978) The physiological characteristics of the primary sensory neurons of the complex tibial organ of Decticus verrucivorus L. (Orthoptera, Tettigoniidae). J Comp Physiol 127:109-121

Kalmring K, Ebendt R, Ahi J, Hellweg J, Young D, Halex $H$ Lakes R, Rössler W, Schröder J (1990) Comparative investigation of the morphology and physiology of the auditory receptor organs of seven species of bushcrickets. In: Gribakin FG, Wiese K, Popov AV (eds) Sensory systems and communication in arthropods. Birkhäuser, Basel, pp 241-247 
Latimer W, Schatral A (1986) Information cues used in male competition by Tettigonia cantans (Orthoptera:Tettigoniidae). Anim Behav 34:162-168

Latimer W, Sippel M (1987) Acoustic cues for female choice and male competition in Tettigonia cantans. Anim Behav 35:887-900

Moiseff A, Pollack G, Hoy R (1978) Steering responses of flying crickets to sound and ultrasound: mate attraction and predator avoidance. Proc Natl Acad Sci USA 75:4052-4056

Nickle AD (1976) Interspecific differences in frequency and other physical parameters in pair forming sounds of bushcrickets (Orthoptera: Tettigoniidae: Phaneropteridae). Ann Entomol Soc Am 69:1136-1144

Nickle AD, Carlysle TC (1975) Morphology and function of female sound-producing structures in ensiferan Orthoptera with special emphasis on Phaneropterinae. Int J Insect Morphol Embryol 4:159-168

Nolen TG, Hoy RR (1986) Phonotaxis in flying crickets. I. Attraction to the calling song and avoidance of bat-like ultrasound. $J$ Comp Physiol A 159:423-439

Oldfield BP (1983) Central projections of primary auditory fibres in Tettigoniidae (Orthoptera: Ensifera). J Comp Physiol 151:389-395

Oldfield BP (1984) Physiology of auditory receptors in two species of Tettigoniidae (Orthoptera: Ensifera). J Comp Physiol A 155:689-696

Oldfield BP, Hill KG (1983) The physiology of ascending auditory interneurons in the tettigoniid Caedicia simplex (Orthoptera: Ensifera): response properties and a model of integration in the afferent auditory pathway. J Comp Physiol 152:495-508

Pires A, Hoy RR (1992) Temperature coupling in cricket acoustic communication. II. Localization of temperature effects on song production and recognition networks in Gryllus firmus. $\mathrm{J}$ Comp Physiol A 171:79-92

Popov AV (1990) Co-evolution of sound-production and hearing in insects. In: Gribakin FG et al. (eds) Sensory systems and communication in arthropods. Birkhäuser, Basel, pp 301-304

Robert D (1989) The auditory behaviour of flying locusts. J Exp Biol 147:279-301

Robinson DJ (1990) Acoustic communication between sexes in bushcrickets. In: Bailey WJ, Rentz DCF (eds) The Tettigoniidae: biology, systematics and evolution. Crawford House Press, Bathurst, pp 112-129

Robinson DJ, Rheinlaender J, Hartley JC (1986) Temporal parameters of male-female sound communication in Leptophyes punctatissima. Physiol Entomol 11:317-323

Römer H (1987) Representation of auditory distance within a central neuropil of the bushcricket Mygalopsis marki. J Comp Physiol A 161:33-42

Schildberger K (1984) Temporal selectivity of identified auditory neurons in the cricket's brain. J Comp Physiol A 155:171-185

Stumpner A, Heller K-G (1992) Morphological and physiological differences of the auditory system in three related bushcrickets (Orthoptera: Phaneropteridae, Poecilimon). Physiol Entomol $17: 73-80$

Zhantiev RD (1971) Frequency characteristics of tympanal organs in grasshoppers (Tettigoniidea). Zool Zh 50:507-514

Zhantiev RD, Korsunovskaya OS (1990) Sound communication of Phaneropteridae (Orthoptera). In: Gribakin FG et al. (eds) Sensory systems and communication in arthropods. Birkhäuser, Basel, pp 402-406

Zimmermann U, Rheinlaender J, Robinson D (1989) Cues for male phonotaxis in the duetting bushcricket Leptophyes punctatissima. J Comp Physiol A 164:621-628 